\title{
Adipose tissue homeostasis is deeply disrupted by doxorubicin treatment
}

\author{
Helena Batatinha ${ }^{1 *}$, Camila Souza', Edson Lima', Maria Isabel Alonso-Vale², Maysa Cruz², Roberta Da Cunha², \\ Fabio Lira', Jose Rosa ${ }^{1}$
}

From Metabolism, Diet and Disease 2014: Cancer and metabolism

Washington DC, USA. 28-30 May 2014

\section{Introduction}

Doxorubicin is an anthracyclin antibiotic commonly used in chemotherapy against several types of cancer, however it has a great number of side effects $[1,2]$. Doxorubicin treatment reduces body weight, affects total cholesterol, free fatty acids and the level of fasting blood glucose [3]. Furthermore this chemotherapy can act to damage the adipocytes increasing the development of insulin resistance in peripheral tissues [1]. Our aim was to investigate the doxorubicin effects on adipocyte tissue and its functions.

\section{Materials and methods}

We performed in vivo studies with 20 male rats, 10 treated 72 hours before the sacrifice with $15 \mathrm{mg} / \mathrm{kg}$ doxorubicin and 10 treated with PBS. We took the retroperitoneal adipocyte tissue to measure lipogenesis, lipolysis, and glucose uptake. We also had an in vitro testing using 3T3-L1 cells treated with doxorubicin to perform toxicity and lipolysis assays.

\section{Results}

Our results showed that in rats, lipogenesis was significantly decreased and lipolysis was also decreased. The glucose uptake test was significantly decreased and the free fatty acids were increased. In vitro assay showed that higher doses (10 and $100 \mathrm{nM}$ concentrations) were toxic, inducing over $90 \%$ cellular apoptosis. Lipolysis in vitro was decreased when the cells were treated with $10 \mathrm{nM}$ for 30 minutes; in this interval this concentration was not toxic because the LDH activity was not modified.

\section{Conclusions}

We can conclude that doxorubicin has many effects upon adipocyte tissue homeostasis, decreasing lipolysis and lipogenesis, glucose uptake and inducing cellular apoptosis in high concentrations, being able to change its function. We are still investigating the molecular mechanisms of this process.

\section{Acknowledgements}

Foundation of Research Support of the State of São Paulo (FAPESP) National Center of Research and technological development (CNPQ)

\section{Authors' details}

'Department of Cell and Developmental Biology, University of São Paulo, São Paulo, Brazil. ${ }^{2}$ Department of Biological Sciences, Institute of Environmental Sciences, Chemical and Pharmaceutical, Federal University of São Paulo, São Paulo, Brazil.

Published: 28 May 2014

\section{References}

1. Arunachalam S, Tirupathi Pichiah PB, Achiraman S: Doxorubicin treatment inhibits PPARgamma and may induce lipotoxicity by mimicking a type 2 diabetes-like condition in rodent models. FEBS Lett 2013, 587:105-110.

2. Buttiglieri S, Ruella M, Risso A, Spatola T, Silengo L, Avvedimento EV, Tarella C: The aging effect of chemotherapy on cultured human mesenchymal stem cells. Exp Hematol 2011, 39:1171-1181.

3. Asensio-Lopez MC, Lax A, Pascual-Figal DA, Valdes M, Sanchez-Mas J: Metformin protects against doxorubicin-induced cardiotoxicity: Involvement of the adiponectin cardiac system. Free Radic Biol Med 2011, 51:1861-1871.

\section{doi:10.1186/2049-3002-2-S1-P5}

Cite this article as: Batatinha et al:: Adipose tissue homeostasis is deeply disrupted by doxorubicin treatment. Cancer \& Metabolism 2014 2(Suppl 1):P5. 